\title{
Transition from rapid processive to slow nonprocessive polyadenylation by vaccinia virus poly(A) polymerase catalytic subunit is regulated by the net length of the poly(A) tail
}

\author{
Paul David Gershon and Bernard Moss ${ }^{1}$ \\ Laboratory of Viral Diseases, National Institute of Allergy and Infectious Diseases, National Institutes of Health, Bethesda, \\ Maryland 20892 USA
}

\begin{abstract}
The mRNA of vaccinia virus, like that of eukaryotes, possesses a poly(A) tail. VP55, the catalytic subunit of the heterodimeric vaccinia virus poly(A) polymerase, was overexpressed and purified to near homogeneity. VP55 polyadenylated a 30-mer primer representing the 3' end of a vaccinia virus mRNA bimodally: $30-35$ adenylates were added in a rapid, processive, initial burst, after which polyadenylation decelerated dramatically and became nonprocessive. Polyadenylation of variants of the 30 -mer primer, which contained preformed $3^{\prime}$-oligo(A) extensions, showed that the transition between the two modes of polyadenylation was regulated by the net length of the $3^{\prime}$-oligo(A) tail rather than the number of adenylate additions catalyzed by VP55. Primers comprising oligo(A) alone were polyadenylated only if they were $>34$ nucleotides in length and, then, only in the slow nonprocessive mode. These data support a dynamic model whereby the mode of polyadenylation by VP55 is regulated by sequences within the $3^{\prime}$ 30-35 nucleotides of the mRNA: Polyadenylation is rapid and processive until a net $3^{\prime}$-oligo(A) length of 30-35 nucleotides is achieved. Consistent with this, excess oligo(A) did not compete with the 30 -mer primer for rapid processive polyadenylation. The primer specificity of VP55 may contribute to the selective polyadenylation of newly formed mRNA.
\end{abstract}

[Key Words: Poly(A) polymerase; polyadenylation; mRNA; 3'-poly(A) tail; vaccinia]

Received April 8, 1992; revised version accepted June 12, 1992.

The 3 '-poly(A) tail characterizes the majority of mRNAs of eukaryotes and their viruses. In vitro studies have shown that in mammalian and yeast cells, endonucleolytic cleavage occurs toward the $3^{\prime}$ end of the nascent transcript prior to polyadenylation (Moore and Sharp 1985; Butler and Platt 1988). In mammalian cells, specific RNA sequences, notably the AAUAAA hexamer and a more degenerate $U$ - or GU-rich element, are required upstream and downstream, respectively, of the cleavage and polyadenylation site /Wickens 1990a; Proudfoot 1991). Fractionation of mammalian nuclear extracts has highlighted roles for multiple protein factors in $3^{\prime}$-end processing, including a poly(A) polymerase (PAP) (Christofori and Keller 1988; Takagaki et al. 1988; Gilmartin and Nevins 1989; Raabe et al. 1991). Biphasic polyadenylation of a "precleaved" mRNA 3 ' end in a HeLa cell nuclear extract has been described: In the first

\footnotetext{
${ }^{1}$ Corresponding author.
}

phase, up to 9 adenylates were added to the RNA in a hexamer-dependent manner; the second phase required an RNA containing a short $3^{\prime}$-oligo(A), was hexamer independent, and was entered upon addition of the tenth adenylate (Sheets and Wickens 1989). The second phase has also been accomplished in vitro by use of purified bovine PAP in conjunction with a bovine protein factor (Wahle 1991a). Additional RNA sequences specify the cytoplasmic extension of poly(A) tails in higher eukaryotes (Wickens 1990b). In yeast, multiple sequence elements may be necessary for the correct formation of mRNA 3 ' ends, the most well-characterized of which appears to be less highly conserved than the mammalian hexamer (Zaret and Sherman 1982; Irniger et al. 1991; Russo et al. 1991).

Vaccinia virus mRNAs, which are synthesized and modified within the cytoplasm of the infected cell, possess poly(A) tails (Nevins and Joklik 1975). Of the three temporal classes of vaccinia virus mRNA identified to date (early, intermediate, late), the early class is the most 
well characterized. Vaccinia early transcripts are synthesized and polyadenylated within the intact infecting virion (Kates and Beeson 1970). Early transcription terminates in response to the sequence UUUUUNU in the nascent transcript (Yuen and Moss 1987; Shuman and Moss 1988a), after which the transcript becomes 3 '-polyadenylated and extruded. A variety of RNAs, including correctly terminated and runoff vaccinia transcripts, can be polyadenylated in virion extracts, which contain the vaccinia-encoded PAP. Neither UUUUUNU nor any other specific sequence appears to be a prerequisite for $3^{\prime}$ polyadenylation in vitro, and specific RNA cleavage events associated with $3^{\prime}$-end formation have not been detected (Rohrmann et al. 1986).

The vaccinia PAP has been purified from both virion and infected cell extracts as a heterodimer (Moss et al. 1975; Nevins and Joklik 1977), comprising the virus-encoded polypeptides VP55 and VP39 (Gershon et al. 1991). Whereas VP55 has been purified only as a heterodimer with VP39, VP39 is present in molar excess over VP55 in both virions and infected cells and, consequently, can be purified in monomeric as well as heterodimeric form (Gershon et al. 1991; P. Gershon and B. Moss, unpubl.). No role in 3' polyadenylation for vaccinia-encoded polypeptides other than VP55 and VP39 has been established, either in vivo or in vitro. Despite an apparently stable association with VP39 during purification, VP55 has been isolated in an immobilized, monomeric form after incubation of the purified heterodimer with VP55-specific IgG and protein A-agarose, and subsequent washes of the solid phase (Gershon et al. 1991). Polyadenylation catalytic activity was associated entirely with the immobilized VP55; however, added VP39 was found to stimulate the formation of long 3 '-poly(A) (Gershon et al. 1991). We have recently shown that VP39, either by itself or in association with VP55, possesses cap-specific nucleoside- $2^{\prime}$ -

methyltransferase activity, indicating that this polypeptide participates in the modification of both ends of the nascent mRNA (Schnierle et al. 1992).

Studies of polyadenylation mechanisms should be facilitated by a detailed characterization of individual components. By overexpression and purification of VP55, we have now established that polyadenylation by this $\operatorname{poly}(\mathrm{A})$ polymerase subunit initiates with a rapid, processive burst and becomes slow and nonprocessive after the addition of $30-35$ adenylates. The parameters affecting the transition between these two modes of polyadenylation and the biological implications of bimodal polyadenylation are discussed.

\section{Results}

\section{Overexpression and purification of VP55}

Previously, PAP was purified as a heterodimer from extracts of vaccinia virions, and monomeric VP55 was isolated from purified heterodimer after binding to VP55specific IgG/protein A-agarose (Gershon et al. 1991). The amounts obtained and the inability to dissociate the
VP55 from IgG under mild conditions were incompatible with comprehensive studies of VP55 function. Because preliminary attempts to overexpress active VP55 in Escherichia coli were unsuccessful, the gene for VP55 was recloned in vaccinia virus under control of a $\mathrm{T} 7$ promoter and a cap-independent leader, and VP55 was overexpressed in HeLa cells by use of the hybrid T7 RNA polymerase-vaccinia virus system (Moss et al. 1990). High levels of VP55, relative to the amounts present in cells infected with wild-type vaccinia virus, were demonstrated by immunoblotting (Fig. 1A). The origin of an additional product of $\sim 42 \mathrm{kD}$ detected on overexpression of VP55 (VP55*; Fig. 1A) was not determined.

A scheme was developed for the purification of overexpressed VP55 from HeLa cell cytoplasmic extract (Fig. 1B). Column fractions were analyzed for VP55 and VP39 by use of specific antisera and assayed for PAP activity through the addition of $\left[\alpha^{-32}\right.$ P $]$ ATP to trichloroacetic acid-precipitable heterogeneous-length poly(A) primer (Moss et al. 1975; Gershon et al. 1991). After the removal of nucleic acid with a DEAE-cellulose (DE52) column, a phosphocellulose (P11) column was used to separate active VP55 from cellular PAPs, VP55/39 heterodimer, putative free VP39, and VP55*. VP55 was then purified to apparent homogeneity by using successive columns of heparin-agarose, Cibacron blue (F3GA)-agarose, and poly(A)-Sepharose. VP39 could not be detected in VP55containing fractions at any stage after phosphocellulose chromatography (data not shown). Silver-stained SDSPAGE of aliquots of fractions from the final column [poly(A)-Sepharose; Fig. 1C] shows the high degree of purity of the resulting VP55.

Aliquots of poly(A)-Sepharose column fractions were assayed for primer-dependent polyadenylation activity with a ${ }^{32} \mathrm{P}$-labeled 30 -nucleotide primer whose sequence matched the $3^{\prime}$ end, before polyadenylation, of a transcript of the vaccinia virus growth factor gene [VGF 30mer primer (Yuen and Moss 1986)|. Activity copurified with VP55 (Fig. ID). In these 60-sec assays, the purified VP55 was able to add no more than 70 adenylates to the VGF 30-mer primer. In contrast, purified heterodimer was able to add $>600$ adenylates under identical assay conditions (Gershon et al. 1991; P. Gershon and B. Moss, unpubl.). Fraction 45 was used for subsequent assays (see below).

\section{VP55 catalyzes a 30- to 35-nucleotide burst of polyadenylation, followed by slow extension}

Polyadenylation of the VGF 30 -mer by VP55 was examined in the presence of either $\mathrm{MnCl}_{2}$ or $\mathrm{MgCl}_{2}$ (Fig. 2). Polyadenylation products were sampled at intervals between 0 and $80 \mathrm{~min}$ and analyzed electrophoretically (Fig. 2A). The length of the poly(A) tail on the most abundant product resolved at each time point was plotted against time (Fig. 2B), as was the amount of unextended primer present as a fraction of the amount present at time zero. During the first $15 \mathrm{sec}$ of the assay, a high initial rate of polyadenylation was observed in the pres- 

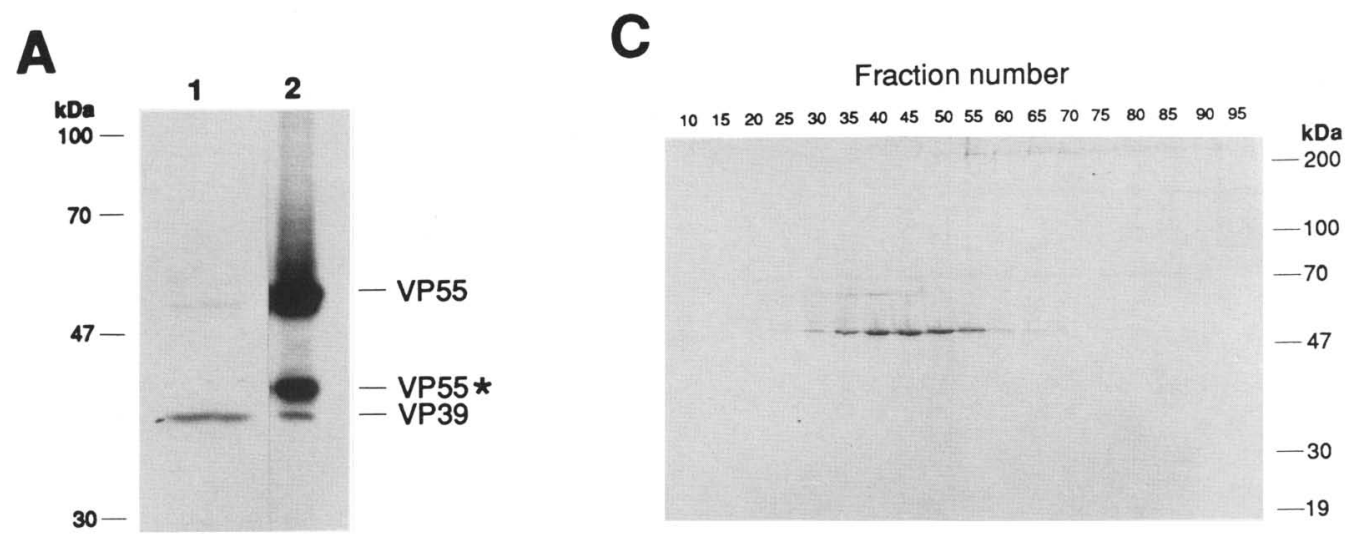

B
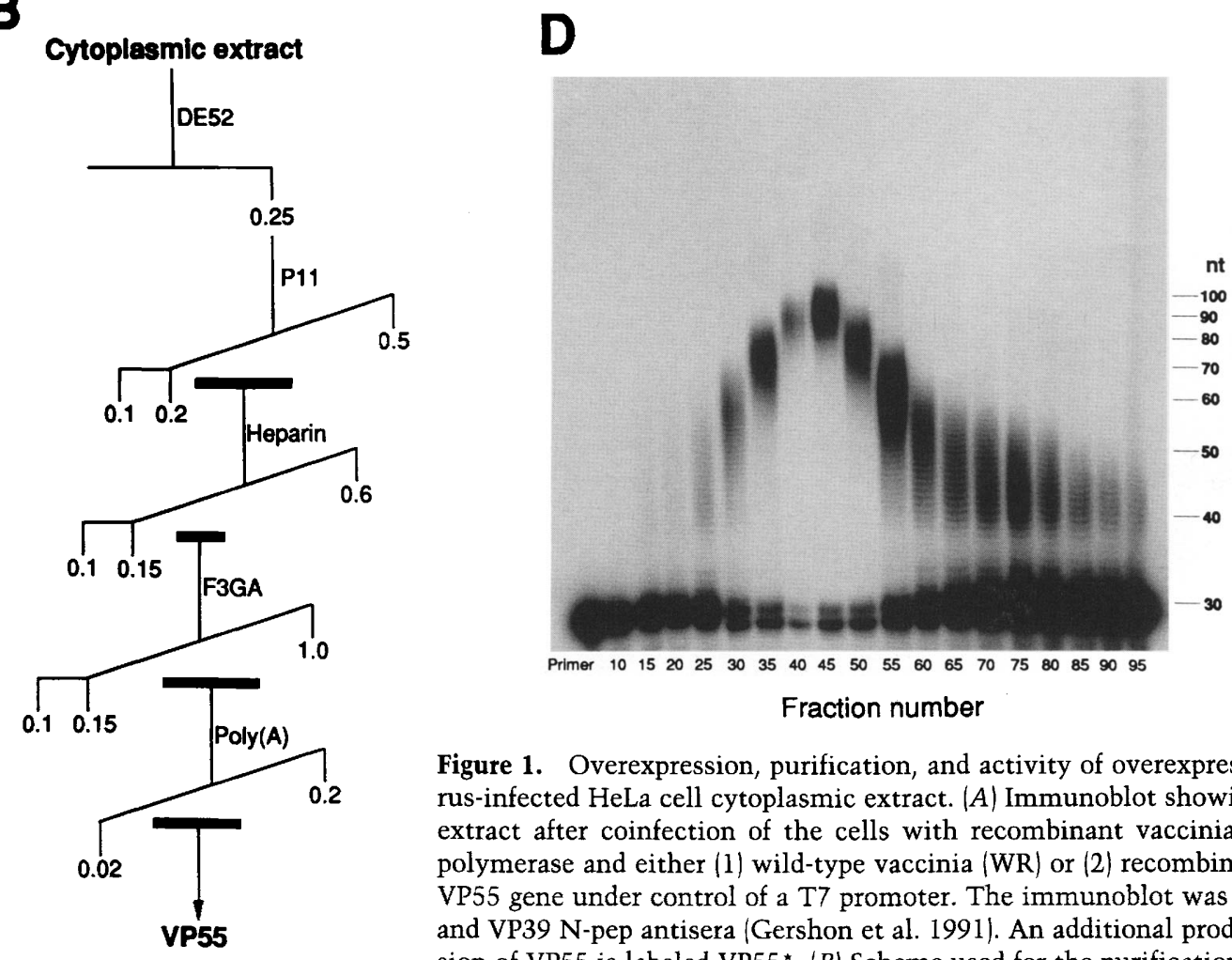

Figure 1. Overexpression, purification, and activity of overexpressed VP55 from vaccinia virus-infected HeLa cell cytoplasmic extract. $(A)$ Immunoblot showing VP55 and VP39 in crude extract after coinfection of the cells with recombinant vaccinia virus expressing T7 RNA polymerase and either (1) wild-type vaccinia (WR) or (2) recombinant vaccinia containing the VP55 gene under control of a T7 promoter. The immunoblot was probed with VP55 C-fusion and VP39 N-pep antisera (Gershon et al. 1991). An additional product detected on overexpression of VP55 is labeled VP55*. (B) Scheme used for the purification of VP55. (C) Silver-stained SDS-PAGE of aliquots of fractions from the final column [poly(A)-Sepharose]. (D) Aliquots of fractions from the final column [poly(A)-Sepharose] assayed for primer (VGF 30-mer)-dependent polyadenylation activity in 60-sec assays. Both $\mathrm{MgCl}_{2}(1 \mathrm{~mm})$ and $\mathrm{MnCl}_{2}(0.6 \mathrm{~mm})$ were present in the assay buffer. The protein concentration in poly(A)-Sepharose column fraction 45 was determined to be $255 \mathrm{nM}$. Primer was therefore present in threefold molar excess over VP55 in the assay of this fraction and a still greater molar excess in the assays of other fractions.

ence of either $\mathrm{MnCl}_{2}$ or $\mathrm{MgCl}_{2}$. This was followed, after a marked deceleration, by steady, slow addition. Extension rates during the initial burst were in excess of 120 adenylate addition per minute in the presence of either $\mathrm{MnCl}_{2}$ or $\mathrm{MgCl}_{2}$. The deceleration in polyadenylation after the initial burst was more pronounced in $\mathrm{MgCl}_{2}$ than in $\mathrm{MnCl}_{2}$, with average extension rates between 20 and $80 \mathrm{~min}$ of 0.25 and 1 additions per minute in $\mathrm{MgCl}_{2}$ and $\mathrm{MnCl}_{2}$, respectively. Additional studies showed that the deceleration did not result from depletion of ATP or inactivation of enzyme (data not shown). More than $95 \%$ of the starting primer was extended within the first $2 \mathrm{~min}$ of the assay in the presence of either $\mathrm{MnCl}_{2}$ or $\mathrm{MgCl}_{2}$.

Polyadenylation assay conditions characterized previously for the virion-derived PAP heterodimer (Moss et al. 1975) (pH 8.5-9.0; divalent cation/ATP ratio of $1 ; \mathrm{NaCl}$ concentration below $50 \mathrm{~mm}$ ) facilitated maximal rates of in vitro polyadenylation by VP55 (data not shown) and were used above (Fig. 2). The initial burst occurred during the first $15 \mathrm{sec}$ under all but the most extremely suboptimal assay conditions and also at reduced assay temperatures $\left(2,6\right.$, and $10^{\circ} \mathrm{C}$; data not shown $)$. 

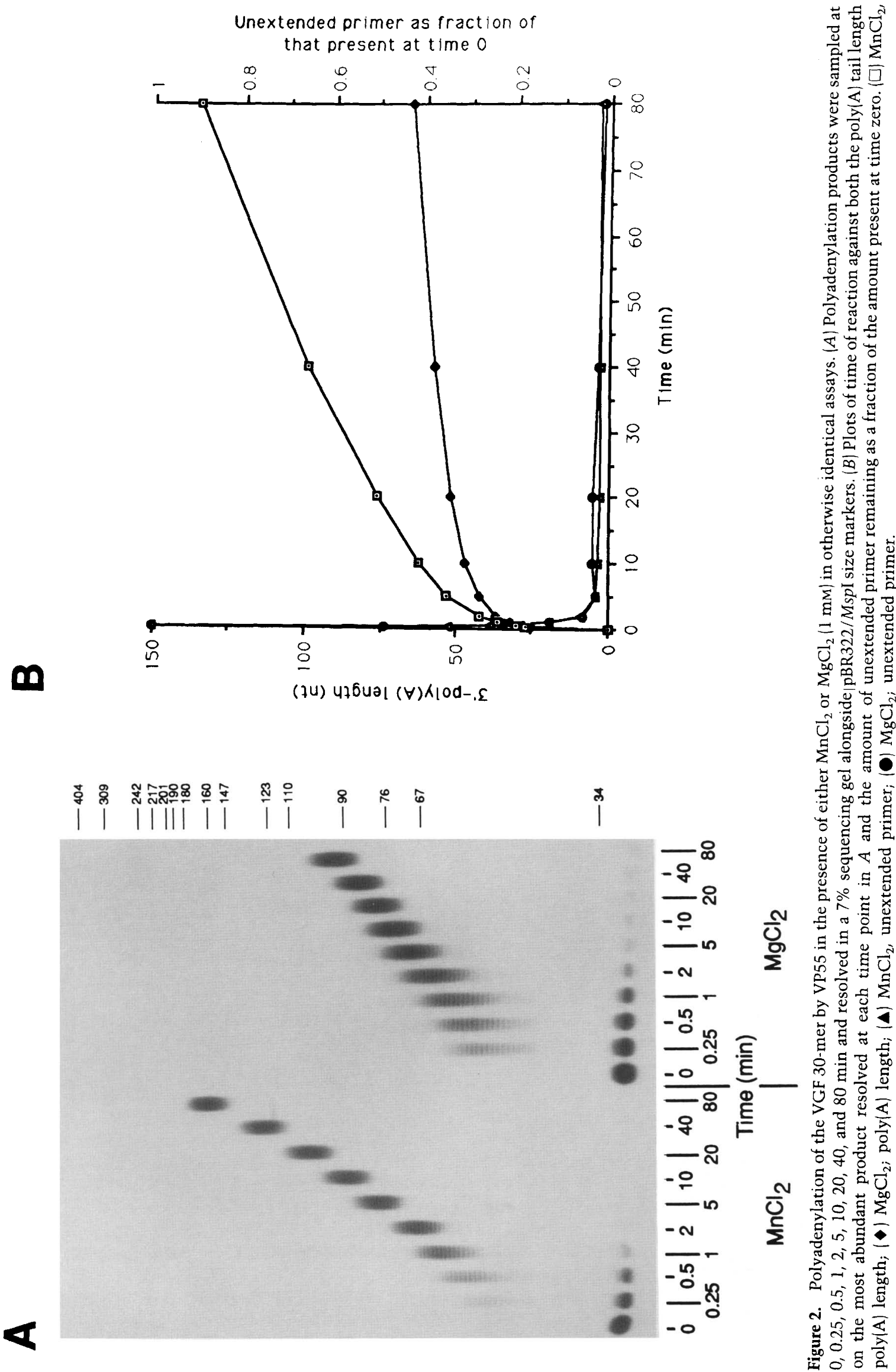


\section{Specificity for AMP addition}

VP55 catalyzed transfer of the nucleoside monophosphate (NMP) moiety of each of four ribonucleoside triphosphates, ATP, UTP, CTP, and GTP, to RNA was examined in the presence of either $\mathrm{MnCl}_{2}$ or $\mathrm{MgCl}_{2}$ (Fig. $3 \mathrm{~A}$ and $\mathrm{B}$, respectivelyl, in 0 - to 2 -min time-course assays. In the presence of $\mathrm{MnCl}_{2}$, transfer from each of the four rNTPs was observed (Fig. 3A), although ATP was by far the most efficient donor. When $\mathrm{MnCl}_{2}$ was replaced with $\mathrm{MgCl}_{2}$ in an otherwise identical assay (Fig. 3B), polyadenylation activity was slightly reduced, as in Figure 2A. In addition, transfer from UTP and CTP was apparently abolished, and the products made in the presence of GTP were greatly reduced in both rate of formation and abundance. Thus, $\mathrm{MgCl}_{2}$ appears to facilitate a stringent incorporation of adenylates into the growing $3^{\prime}$-poly(A). Because $\mathrm{Mg}^{2+}$ is presumably a more physiologically relevant divalent cation than $\mathrm{Mn}^{2+}, \mathrm{MgCl}_{2}$ was used exclusively in subsequent assays (described below).

\section{Processivity}

We refer to the processivity of primer-dependent PAP as its ability to catalyze nucleotide additions without separating from the growing chain. Under conditions in which primer was present in molar excess over polymer- ase, a completely nonprocessive polymerase would extend all primer molecules at an equal rate, whereas a highly processive polymerase would extend some primer molecules and leave others unextended. The processivity of VP55 was examined by assaying polyadenylation at VGF 30-mer primer/VP55 molar ratios of between 1 and 81. Various amounts of VP55 were assayed in the presence of a fixed amount of primer in 0- to 2-min (Fig. 4A) and $0-$ to $80-\mathrm{min}$ (Fig. 4B) time-course assays. At a ratio of 1 , the usual rapid burst of polyadenylation was observed, accompanied by a depletion of the unextended primer and a fairly uniform slow extension of all of the products. With increases in the primer/VP55 molar ratio, proportionately less of the primer was extended. The initial burst of addition of 30-35 adenylates, however, occurred at the same rate for individual primer molecules. At high primer/VP55 ratios, there was a continuous accumulation of primer extended by 30-35 adenylates; but considerable unextended primer remained, and the slow uniform addition phase of polyadenylation was largely suppressed. These observations best fit a model in which VP55 processively adds $30-35$ adenylates to the starting primer and then dissociates. VP55 can then, cyclically, either processively extend additional molecules of starting primer or nonprocessively add adenylates to those already extended. Thus, we suggest that VP55 catalyzes polymerization both processively and nonprocessively, depending on the phase of the reaction. Further
A

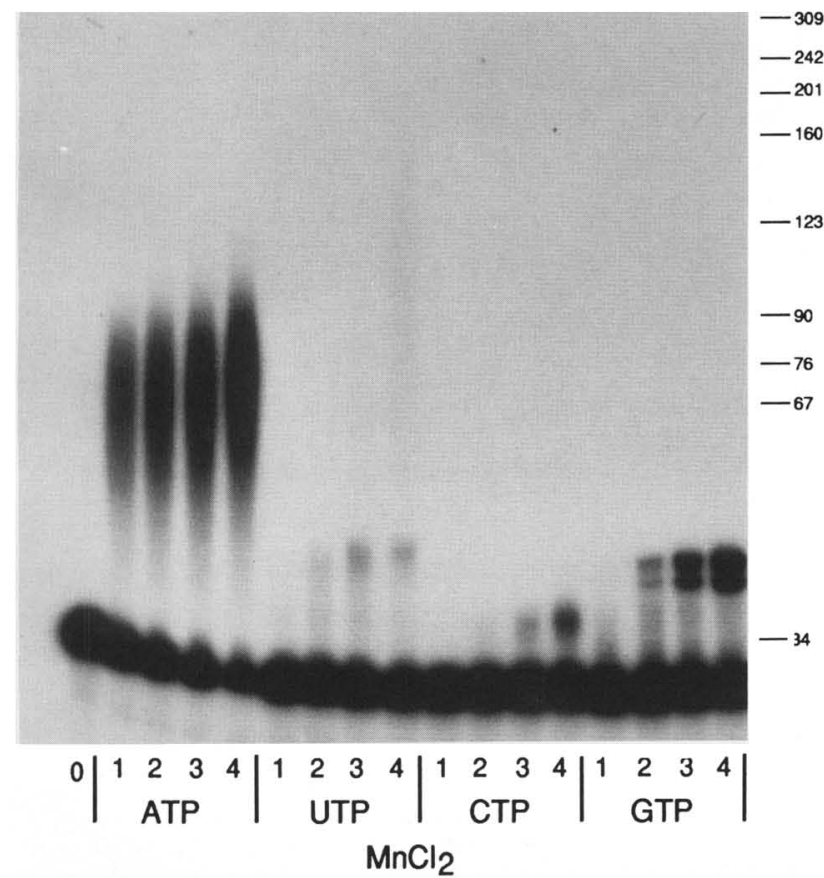

B

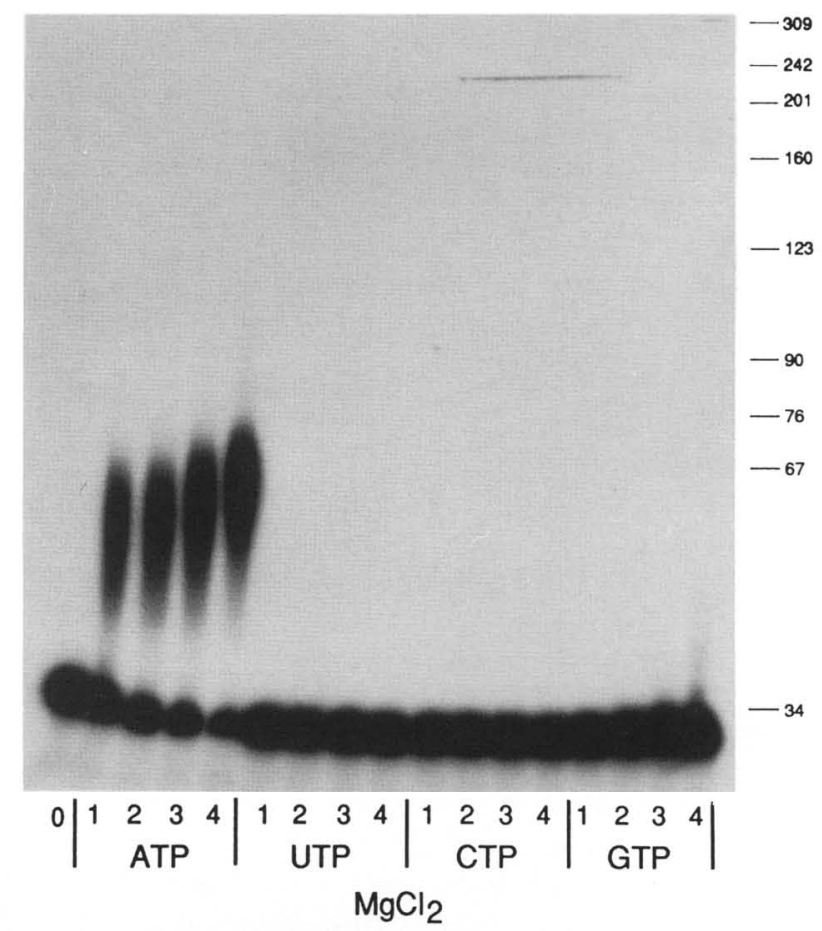

Figure 3. Ribonucleoside triphosphate specificity of VP55 in the presence of $\mathrm{MnCl}_{2}$ or $\mathrm{MgCl}_{2}$. Transfer of the NMP moiety of each of four ribonucleoside triphosphates, ATP, UTP, CTP and GTP to RNA, was assayed in the presence of $1 \mathrm{mM} \mathrm{MnCl}_{2}(A)$ and $1 \mathrm{mM}$ $\mathrm{MgCl}_{2}(B)$; numbers $0,1,2,3$, and 4 designate products sampled at $0,15,30,60$, and 120 sec, respectively. 
A

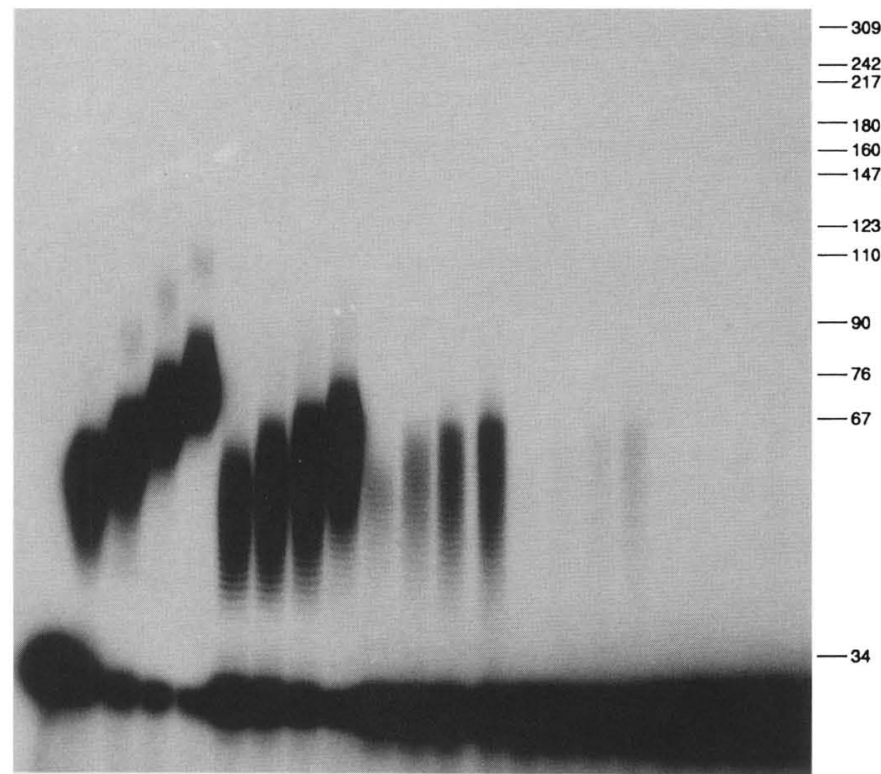

$0\left|\begin{array}{cccc|cccc|cccc|cccc|cccc}1 & 2 & 3 & 4 & 1 & 2 & 3 & 4 & 1 & 2 & 3 & 4 & 1 & 2 & 3 & 4 & 1 & 2 & 3 & 4 \\ & 1 & & & 3 & & 9 & & 27 & & 81\end{array}\right|$

Primer:VP55 molar ratio
B

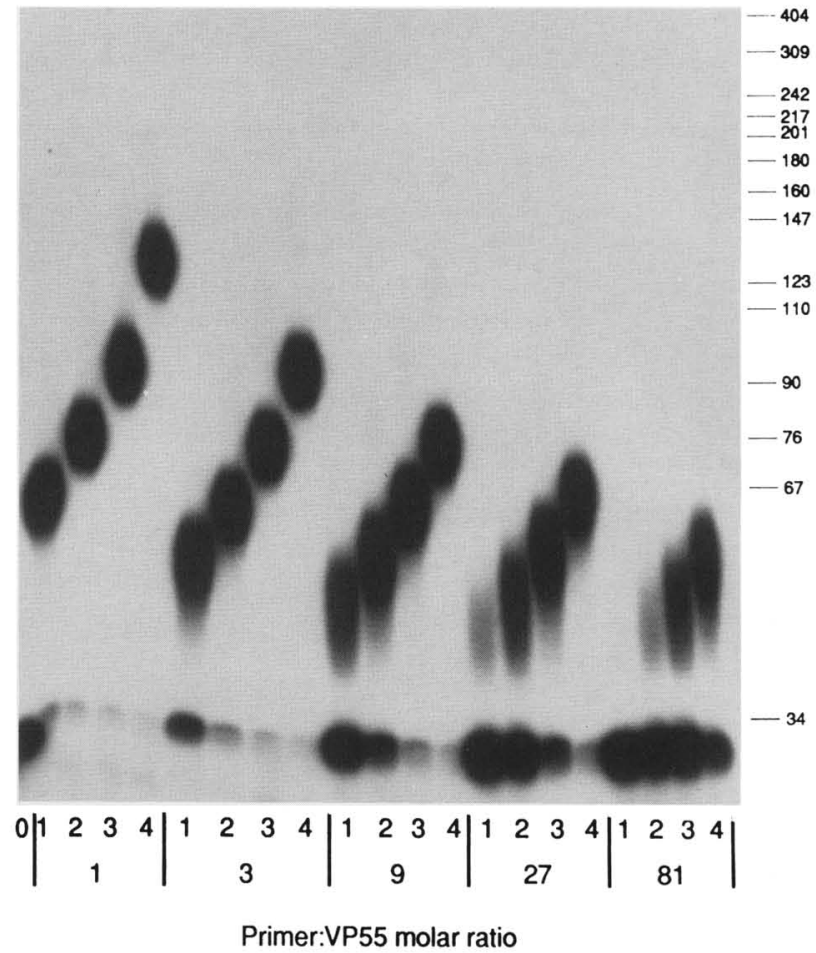

Figure 4. Processivity of polyadenylation of the VGF 30-mer by VP55. Primer/VP55 molar ratios between 1 and 81 (lower set of numbers below each panel) were assayed by mixing aliquots from progressive threefold dilutions of VP55 (made in buffer B $+0.1 \mathrm{M}$ $\mathrm{NaCl}$ ) with a fixed amount of primer. Numbers $0,1,2,3$, and 4 (upper set of numbers below each panel) designate products sampled at $0,15,30,60$, and $120 \mathrm{sec}$, respectively $(A)$ and $0,1,5,20$, and $80 \mathrm{~min}$, respectively $(B)$.

experiments were designed to determine the parameters affecting the transition between the two polyadenylation modes.

\section{The transition from processive burst}

to nonprocessive slow extension is caused by the presence of $3^{\prime}$-oligo $(A)$ with a net length of 30-35 nucleotides

The transition from rapid, processive to slow, nonprocessive extension could have been caused by (1) the iterative addition of $30-35$ adenylates to the growing RNA (2) extension of the $3^{\prime}$-oligo(A) to a net length of 30-35 residues, or $|3|$ extension of the primer to an overall length of 60-65 nucleotides. To address these alternatives, the 30 -mer primer and two primers identical to the 30-mer except for the presence of preformed, 3 '-oligo(A) extensions of 15 or 25 residues, were polyadenylated (Fig. $5 \mathrm{~A})$. Thirty to thirty-five adenylates were added to the 30-mer during the initial 15- to 30-sec period; correspondingly fewer adenylates were added to the 30-merA15 primer, and there was essentially no burst with the 30-mer-A25 primer, just slow extension. Because the primers were each extended to a similar length with time, the transition from the rapid processive to the slow nonprocessive mode of extension was regulated by the net length of the $3^{\prime}$-oligo(A) tail or the length of the RNA, rather than by the number of adenylate additions catalyzed by VP55.

To distinguish whether the transition was caused by the net length of the $3^{\prime}$-oligo(A) or by the length of the RNA, a different-sized but related primer (110 nucleotides in length and $3^{\prime}$-coterminal with the 30 -mer) was polyadenylated by VP55 in a 0 - to 2-min time-course assay (Fig. 5B). As with the 30-mer, 30-35 adenylates were added during the initial burst, indicating that the transition was caused by the $3^{\prime}$-oligo(A) length rather than the overall RNA length. The 110-mer also differed from the 30-mer in containing two copies of the UUUUUNU transcriptional termination signal. This evidently has no role in polyadenylation by VP55. On polyadenylation of many other primers of various size and sequence, regulation by the length of the $3^{\prime}$-oligo(A) moiety was also observed (data not shown).

The processive burst of polyadenylation requires non-poly $(A)$ sequences

Transition between the two modes of extension corresponded with the presence of $3^{\prime}$-oligo(A) of 30-35 nucle- 

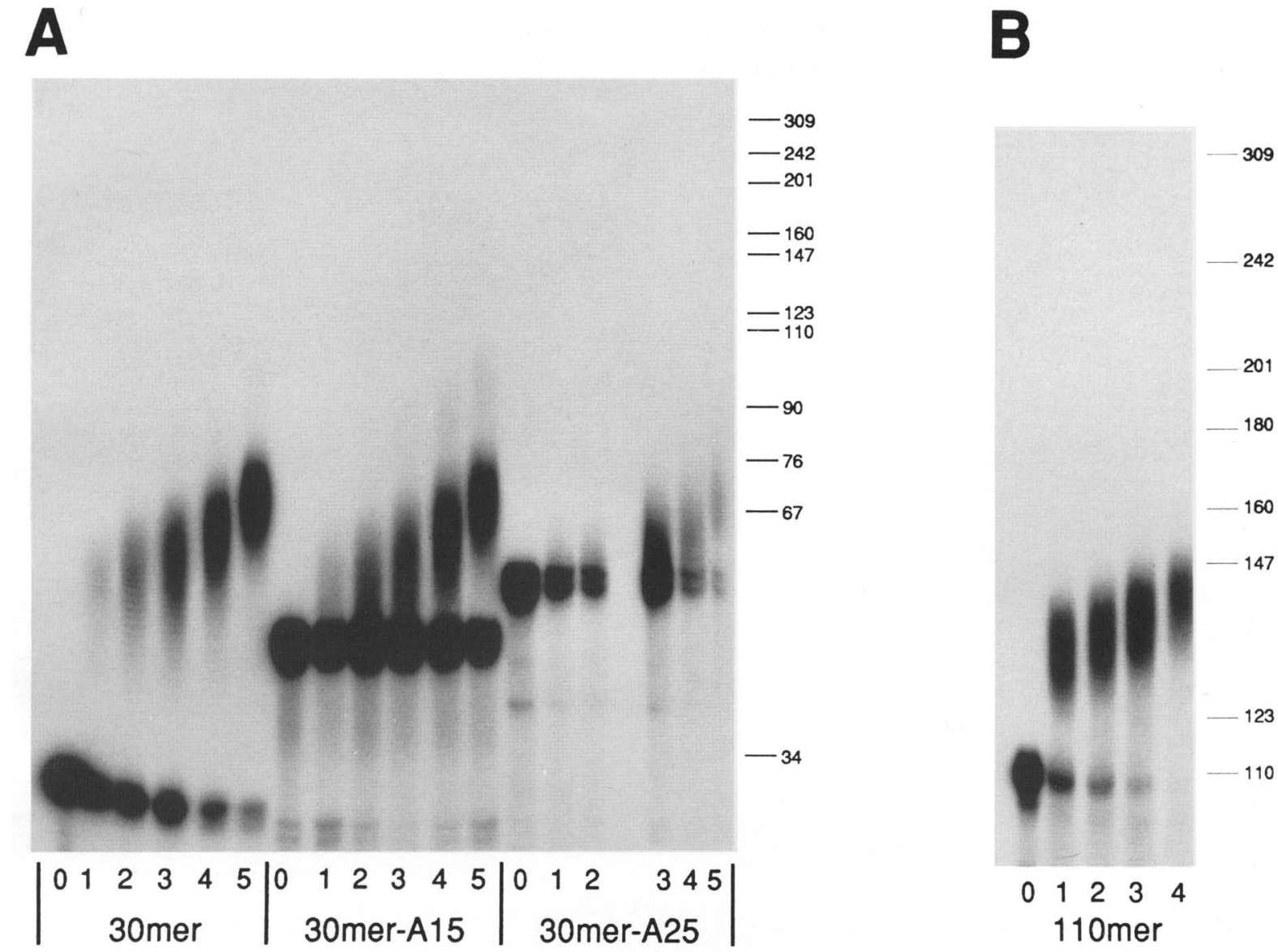

Figure 5. The transition from fast, processive to slow, nonprocessive extension is regulated by the length of $3^{\prime}$-oligo(A). The following primers were polyadenylated: $(A)$ the VGF 30 -mer and derivatives of the 30-mer with preformed $3^{\prime}$-A15 and $3^{\prime}$-A25 extensions; $(B)$ the VGF 110-mer. Numbers $0,1,2,3,4$, and 5 designate products sampled at $0,15,30,60,120$, and 300 sec, respectively.

otides on the growing RNA. Therefore, we determined whether poly(A) alone was sufficient to prime processive or nonprocessive extension. VP55 was incubated with poly(A) primers of various sizes between 25 and 200 residues. An initial burst of polyadenylation was not observed, although poly $(\mathrm{A})$ primers $>50$ nucleotides in length were extended slowly (data not shown). To define the minimum size required for slow extension, oligo(A) primers of $19,24,29,34,38,42$, and 45 nucleotides were polyadenylated in 0 - to 80 -min time-course assays (Fig. 6A). As noted above, an initial burst of polyadenylation was not observed; however, the oligo(A) primers with a starting length of 38 nucleotides or greater were slowly polyadenylated, whereas there was essentially no polyadenylation of those with a starting length of 34 nucleotides or less.

The processivity of the slow extension of oligo(A) was determined by incubating a fixed amount of the primer $\mathrm{A}_{50}$ with various amounts of VP55 to give primer/VP55 molar ratios of between 0.67 and 54 (Fig. 6B). At each primer/VP55 ratio the majority of the primer molecules were extended, but each increase in ratio correlated with a decrease in the average extension rate. Thus, polyade- nylation was entirely nonprocessive in character. We conclude that oligo(A) primers do not support an initial burst of polyadenylation, but those greater than 34-38 nucleotides in length are polyadenylated in the slow, nonprocessive mode.

\section{Nonprocessive does not competitively inhibit processive extension}

The ability of primers that are extended in the slow nonprocessive mode to competitively inhibit the polyadenylation of a primer that could be processively extended was examined. Labeled VGF 30 -mer was mixed with various excess amounts of the unlabeled primer $\mathrm{A}_{50}$, prior to the addition of VP55 (Fig. 7). Even a 30-fold molar excess of $\mathrm{A}_{50}$ did not detectably affect the extension rate during the processive initial burst of polyadenylation of the 30mer. A 30-fold excess of $A_{50}$, however, slightly reduced both the rate at which successive rounds of processive extension of the 30-mer occurred during the assay and the rate of slow nonprocessive extension of the oligoadenylated 30-mer. 
A

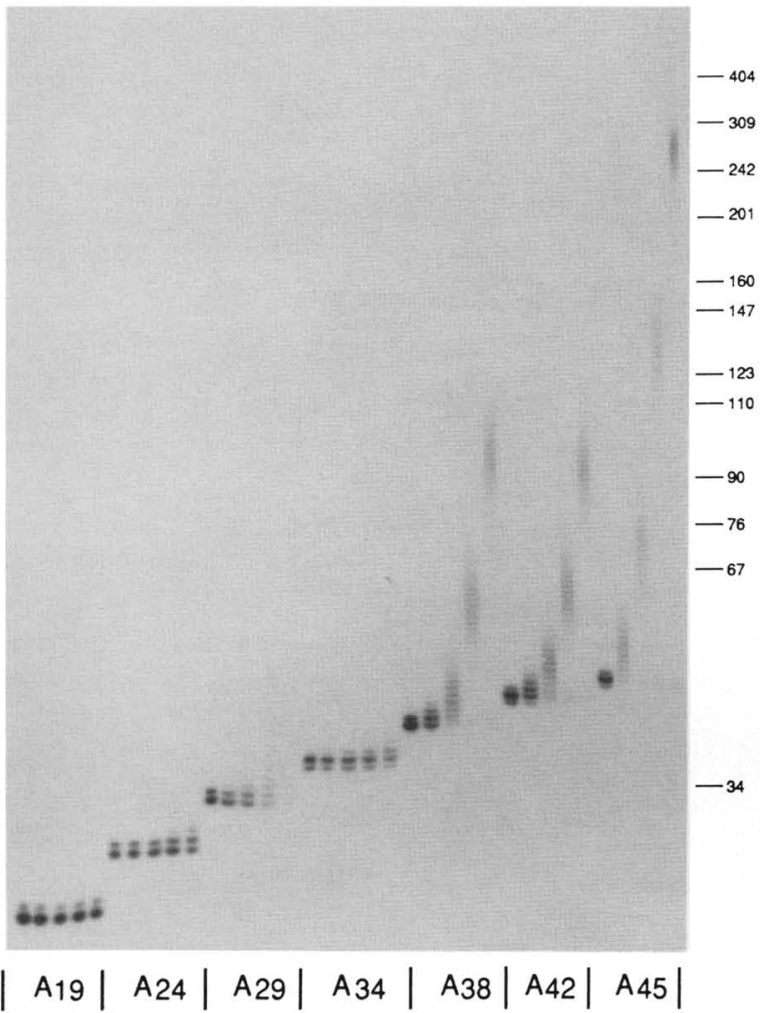

B

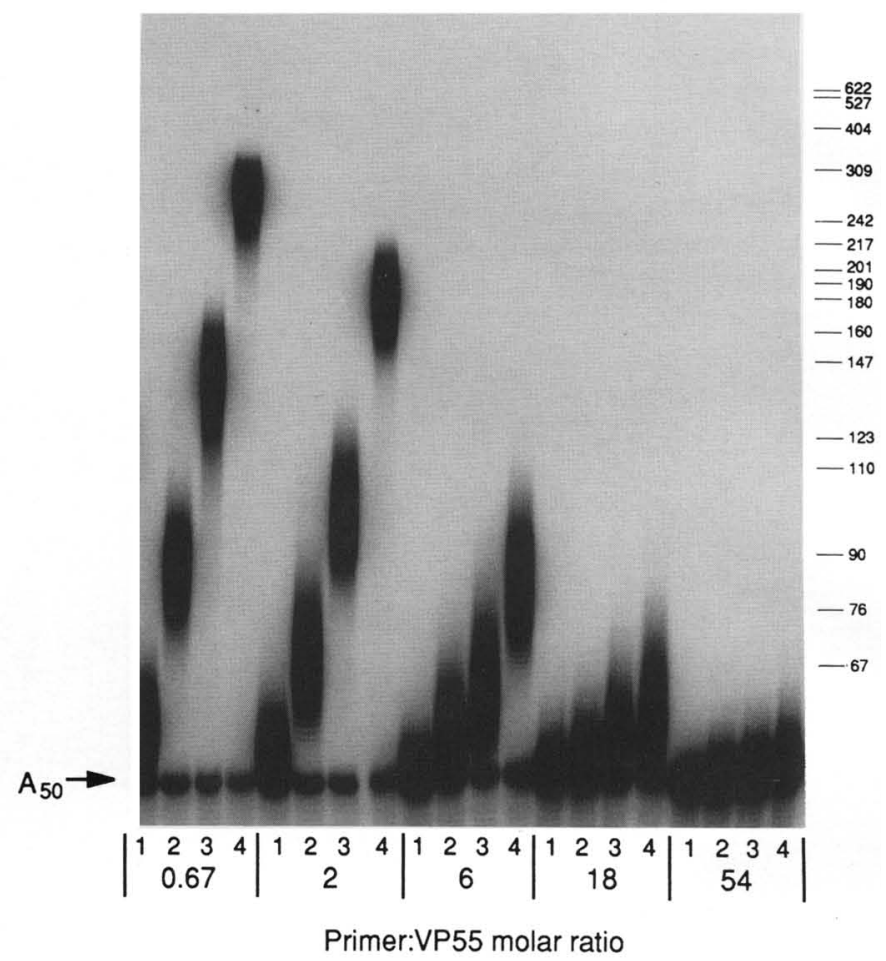

Figure 6. Polyadenylation of primers comprising oligo(A) alone. $(A)$ By incubating oligo(A) primers of various sizes between 19 and 45 nucleotides with VP55, a minimum length of oligo(A) required for slow extension was identified. As a result of a 2-or 3-nucleotide size heterogeneity in each of the primer preparations, the most abundant species in each preparation is denoted. In each assay, products were sampled at $0,1,5,20$, and $80 \mathrm{~min}$. $(B)$ The primer $A_{50}$ is extended nonprocessively. Polyadenylation was assayed at primer/VP55 molar ratios between 0.67 and 54 (lower set of numbers), by mixing aliquots from progressive threefold dilutions of VP55 (made in buffer $\mathrm{B}+0.1 \mathrm{M} \mathrm{NaCl}$ ) with a fixed amount of primer. Numbers $0,1,2,3$, and 4 (upper set) designate products sampled at 0 , 1, 5, 20, and $80 \mathrm{~min}$, respectively. Products were resolved in an $8 \%$ gel.

\section{Discussion}

The VP55 subunit of vaccinia virus PAP was overexpressed and purified to near homogeneity. The enzyme rapidly added 30-35 adenylates to an RNA primer, followed by a dramatic deceleration in polyadenylation. Optimal activity was observed with equivalent concentrations of divalent cation and ATP, suggesting that the coordinated complex is recognized by VP55. Although the catalytic activity of VP55 was slightly greater in the presence of $\mathrm{MnCl}_{2}$ than $\mathrm{MgCl}_{2}$, there was a greater specificity for ATP incorporation in the presence of $\mathrm{MgCl}_{2}$. Various effects of divalent cations on the activities of eukaryotic PAPs have been observed, owing to the different sources and purities of PAP and the apparently multiple roles of $\mathrm{Mg}^{2+}$ in eukaryotic mRNA 3'-end formation (Takagaki et al. 1988; Christofori and Keller 1989; Ryner et al. 1989; Edmonds 1990; Lingner et al. 1991a; Wahle 1991b).

The sequences of the two principal RNA primers used in this study match the $3^{\prime} 30$ and 110 nucleotides of a vaccinia virus early mRNA before polyadenylation.
There is considerable evidence that the $3^{\prime}$ end of this mRNA was formed by transcriptional termination downstream of the RNA sequence UUUUUNU. Although this sequence was only present in the longer of the two primers, 30-35 adenylates were added to either primer in a processive burst. In the presence of a molar excess of primer over VP55, a continuous recycling of VP55 led to the processive extension of additional primer molecules; and with extension of all of the starting primer, slow nonprocessive polyadenylation became predominant. Processivity was determined by assaying polyadenylation at various primer/VP55 molar ratios. Other methods for determining processivity, such as primer challenge, were not feasible owing to the high rate of the initial burst under all but the most extreme assay conditions, even at temperatures as low as $2^{\circ} \mathrm{C}$.

Because polyadenylation was occurring in both processive and nonprocessive modes, we wished to determine whether the transition between the two was regulated by the catalytic addition of $30-35$ adenylates by VP55 or by the net length of the growing 3 '-oligo(A) tail, that is, whether VP55 counted or measured substrate molecules. 


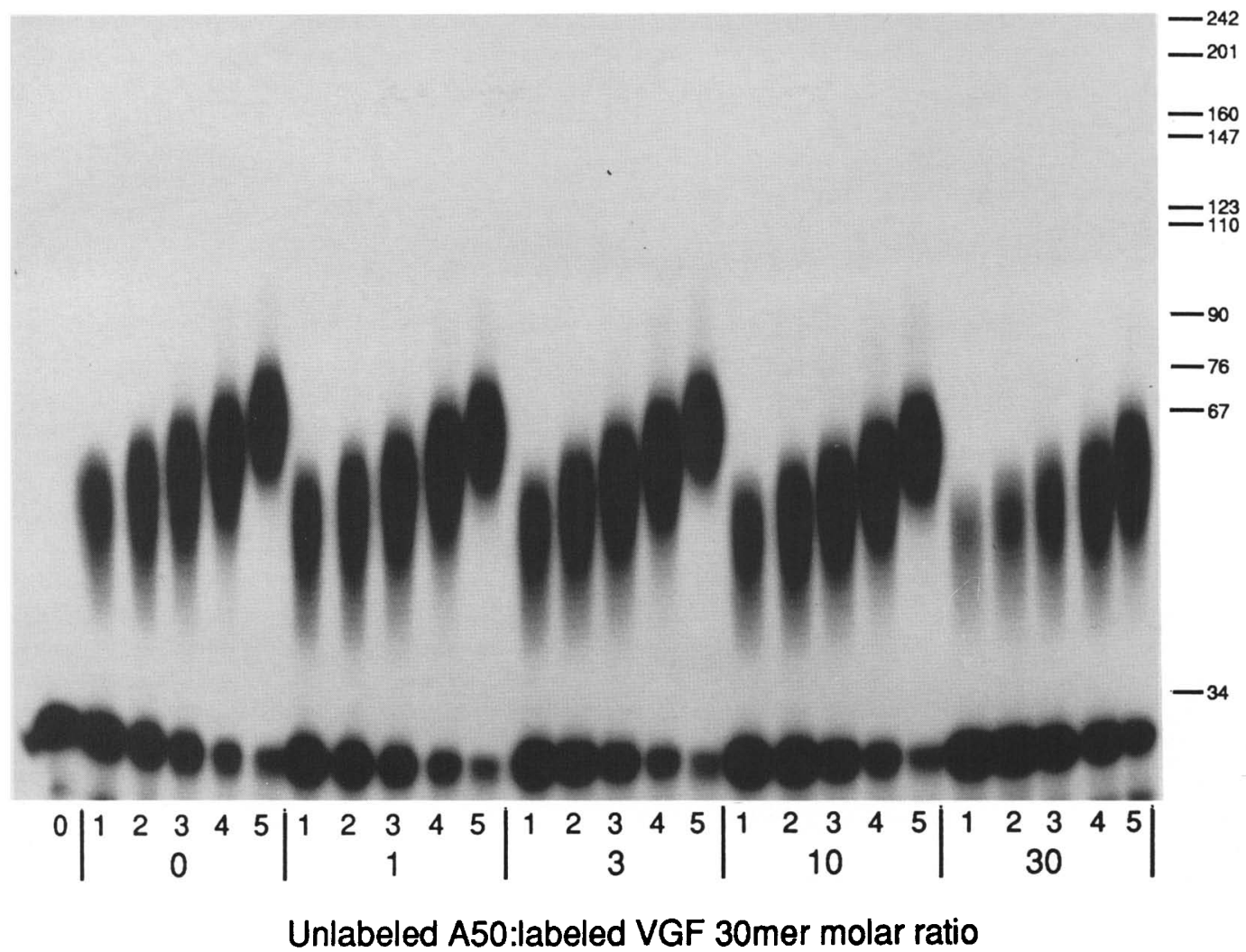

Figure 7. Competition for polyadenylation between unlabeled $\mathrm{A}_{50}$ and labeled VGF 30-mer. Unlabeled $\mathrm{A}_{50} /$ labeled VGF 30-mer molar ratios of 0 (no $A_{50}$ present), 1, 3, 10, and 30 were assayed (lower set of numbers). The VGF 30-mer was present in $3.6 \times$ molar excess over VP55 in each assay. Numbers $0,1,2,3,4$, and 5 (upper set) designate products sampled at $0,15,30,60,120$, and 300 sec, respectively.

Evidence for the latter mode of action was obtained by using primers with preformed oligo(A) tails. With a starting primer containing a preformed oligo(A) tail of 15 adenylates, the number of additional adenylates incorporated during the initial rapid burst dropped from between 30 and 35 to between 15 and 20 . With a preformed tail of 25 adenylates, only slow nonprocessive extension was observed. Primers composed of oligo(A) alone could be polyadenylated, but only slowly and nonprocessively, and only if the starting length of the primer was $>34$ nucleotides. Extension kinetics resembling those of VP55 have not been demonstrated with other nontemplated DNA or RNA polymerases, such as terminal deoxynucleotidyl transferase /Coleman and Deibel 1983), polynucleotide phosphorylase (Littauer and Soreq 1982), or other PAPs (Edmonds 1990).

Processive and nonprocessive polyadenylation could result from differences in the affinity of VP55 for sequences at the $3^{\prime}$ end of the primer. Loss of processivity could then result from a low affinity of VP55 for 3 '-oligo(A). Because both oligo(A) $>31-38$ nucleotides in length and 3 '-oligo(A) extensions of similar length attached to the VGF 30-mer were polyadenylated nonprocessively, VP55 may interact with a 31- to 38-nucleotide segment of oligo(A). The inability of oligo(A) shorter than this length to act as a primer would indicate that oligo(A) must contact or fill regions at both ends of the putative binding site for nonprocessive polyadenylation to occur. The ability to distinguish polyadenylated from nonpolyadenylated RNA molecules could provide an advantage in vivo. Thus, a large molar excess of the primer $\mathrm{A}_{50}$, a paradigm for $3^{\prime}$-polyadenylated $\mathrm{mRNA}$, was found not to compete effectively with non-poly(A) primers.

In vivo, the vaccinia polyadenylation machinery presumably distinguishes newly formed mRNA from other nonpolyadenylated RNA species. Specific RNA sequence determinants mediating recognition and an initiating processive burst of polyadenylation by VP55, however, have not been found. The transcriptional termination signal UUUUUNU was not present in the VGF 30 -mer primer and is therefore not required. Highly specific sequences may not be required for processive polyadenylation by VP55. In this respect, yeast mRNA 3 '-end definition and polyadenylation appears to correlate with degenerate AT- or AU-rich sequences close to the polyadenylation site (Zaret and Sherman 1982; Osborne and Guarente 1989; Romanos et al. 1991; Russo et al. 1991). Specificity for newly formed transcripts may be conferred by a supramolecular juxtaposition of VP55 with the transcriptional machinery. Vaccinia virus capping enzyme and multisubunit RNA polymerase associate in vitro, suggesting that mRNA specificity for 5 '-end capping may occur in vivo through such an interaction (Broyles and Moss 1987; Hagler and Shuman 1992). 
Despite an absence of overall similarity in primary structure between VP55 and those eukaryotic PAPs for which genes have been identified (Gershon et al. 1991; Lingner et al. 1991b; Raabe et al. 1991), at least three functional comparisons may be drawn: Like VP55, the most highly purified preparations of the bovine and yeast enzymes extend oligo(A) primers slowly and nonprocessively (Lingner et al. 1991a; Wahle 1991b) although, unlike VP55, they are active with very short oligo(A) primers. Second, $\mathrm{Mg}^{2+}$-dependent polyadenylation of a mammalian "precleaved" mRNA 3' end by highly purified bovine PAP requires the presence of an AAUAAAspecific multisubunit specificity factor (Wahle 1991a). Because VP55 can polyadenylate a natural vaccinia mRNA $3^{\prime}$ end, this polypeptide may combine functions possessed by mammalian PAP and components of the specificity factor. Third, the slow polyadenylation of a mammalian precleaved mRNA $3^{\prime}$ end in the presence of purified bovine PAP and AAUAAA-specific specificity factor is considerably accelerated in the presence of a second bovine factor, and the accelerated polyadenylation of an RNA possessing 3 '-oligo(A) requires only the second factor and bovine PAP (Wahle 1991a). The activity of the bovine second factor and PAP is comparable to that of a combination of VP55 and VP39.

Previous and current in vitro data suggest that vaccinia virus $3^{\prime}$-poly(A) tail formation can be divided into phases of initiation, elongation, and termination. In the initiation phase, the nonpolyadenylated mRNA $3^{\prime}$ end is recognized by VP55 and is rapidly and processively tagged with oligo(A) of 30-35 nucleotides. In the elongation phase, VP39 can stimulate a rapid extension of $3^{\prime}$ poly(A), possibly by preventing VP55 from dissociating from the RNA molecule on which synthesis has initiated (P. Gershon and B. Moss, unpubl.). The nonprocessive mode of polyadenylation by VP55 alone may thus not be significant in vivo both because of its low rate and the intervention of VP39. In the final phase, the terminal $3^{\prime}$-poly(A) length is regulated. Although tails $>600 \mathrm{nu}-$ cleotides can be synthesized in vitro, vaccinia transcripts contain shorter and more defined tails in vivo. Tail length might be regulated in vivo by a dissociation of VP55 or VP39 from the elongation complex. This may be achieved through the intervention of an additional factor, possibly in combination with an RNA sequence or structure, or it may simply result from the weak association between VP39 and VP55. Although a purified heterodimer of VP55 and VP39 can be obtained by conventional protein chromatography and sedimentation steps, the association of the two polypeptides is not stable and can be disrupted by using specific IgG and by other means (Gershon et al. 1991; P. Gershon and B. Moss, unpubl.). The interactions of VP39, VP55, and RNA are presently under investigation.

\section{Materials and methods}

Recombinant vaccinia virus and VP55 expression

Plasmid pPG172a was made by cloning a polymerase chain reaction (PCR) copy of the vaccinia virus ElL gene-coding region in the expression vector pTM1 (Moss et al. 1990). The activity of the expressed product of pPG172a was checked by in vitro transcription and translation, and immunopurification and assay of the product [filter-binding PAP assay, (Gershon et al. 1991)]. Vaccinia virus vPG172a was made from pPG172a as described (Moss et al. 1991). HeLa cells (50 x 10') were coinfected for $18 \mathrm{hr}$ with vPG172a and vTF7-3 (Fuerst et al. 1986), each at $10 \mathrm{PFU} /$ cell.

\section{Purification of VP55}

Cells were harvested, allowed to swell in $10 \mathrm{mM}$ Tris- $\mathrm{HCl} / \mathrm{pH}$ 8.0), $1 \mathrm{mM}$ EDTA, $5 \mathrm{~mm}$ DTT, $63 \mu \mathrm{g} / \mathrm{ml}$ of PMSF, and 1.25 $\mu \mathrm{g} / \mathrm{ml}$ of pepstatin and were Dounce homogenized. The supernatant present after successive centrifugation steps at $1500 \mathrm{~g}$ for $10 \mathrm{~min}$, then at $120,000 \mathrm{~g}$ for $2 \mathrm{hr}$, was adjusted to $15 \%$ (vol/vol) in glycerol and $250 \mathrm{mM}$ in $\mathrm{NaCl}$ and applied to a DEAE-cellulose (DE52, Whatman) column that had been equilibrated with buffer A [50 mM Tris- $\mathrm{HCl}(\mathrm{pH} 8.0), 15 \%$ (vol/vol) glycerol, 0.1 mM EDTA, $2 \mathrm{~mm}$ DTT] containing $250 \mathrm{~mm} \mathrm{NaCl}$. Pooled protein-containing flowthrough fractions were diluted with buffer A to $0.1 \mathrm{M} \mathrm{NaCl}$ and applied to a phosphocellulose (P11, Whatman/ column. After extensive washing with buffer A containing $0.2 \mathrm{M} \mathrm{NaCl}$, the column was eluted with a linear gradient of $0.2-0.5 \mathrm{M} \mathrm{NaCl}$ in buffer A. VP55-containing fractions were identified by the filter-binding PAP assay and by immunoblotting (Gershon et al. 1991). These fractions were pooled, diluted to $0.1 \mathrm{M} \mathrm{NaCl}$ with buffer $\mathrm{A}$, and applied to a heparin-agarose (GIBCO-BRL) column. The column was washed with $0.15 \mathrm{M}$ $\mathrm{NaCl}$ in buffer $\mathrm{A}$, and eluted with a linear gradient of $0.15-0.6$ $\mathrm{M} \mathrm{NaCl}$ in buffer A. VP55-containing fractions were pooled, diluted to $0.1 \mathrm{M} \mathrm{NaCl}$ with buffer $\mathrm{A}$, and applied to a Cibacron blue (F3GA)-agarose (Affigel blue; Bio-Rad) column. The column was washed with $0.15 \mathrm{M} \mathrm{NaCl}$ in buffer $\mathrm{A}$ and eluted with a linear gradient of $0.15-1 \mathrm{M} \mathrm{NaCl}$ in buffer A. VP55-containing fractions were pooled, diluted to $20 \mathrm{mM} \mathrm{NaCl}$ with buffer $\mathrm{A}$ containing $20 \%$ (vol/vol) glycerol (buffer B), and applied to a poly(A)-Sepharose (Pharmacia) column. The column was washed with $20 \mathrm{mM} \mathrm{NaCl}$ in buffer $\mathrm{B}$ and eluted with a linear gradient of $20-200 \mathrm{~mm} \mathrm{NaCl}$ in buffer B. Protein in the VP55containing fractions was quantified by the method of Cheley and Bayley (1991).

\section{RNA primers}

The VGF 30-mer and VGF 110-mer primers are 3 '-coterminal, and correspond to the $3^{\prime}$-terminal 30 or 109 nucleotides (before polyadenylation) of a polyadenylated vaccinia virus transcript, as identified by cDNA cloning (Yuen and Moss 1986). The VGF 30-mer-related primers (5'-UUAUAAAAAUGCUAAGUAUGCGAUGUAUCU-3'), containing 3'-oligo(A) extensions and the primer $A_{50}$, were chemically synthesized by use of phosphoramidite chemistries and were purified from $20 \%$ polyacrylamide $/ 7 \mathrm{M}$ urea gels with standard crush-and-soak methods. The VGF 110-mer, which contained an additional $55^{\prime}-\mathrm{G}$ residue, was synthesized from a PCR-derived template by use of $\mathrm{T} 7$ RNA polymerase, dephosphorylated with calf-intestinal phosphatase (CIP; Boehringer Mannheim), and purified from a $14 \%$ polyacrylamide/7 $\mathrm{M}$ urea gel.

To isolate poly(A) primers of discrete size, heterogeneous poly(A) (ICN) was CIP-treated, phenol-chloroform extracted, ethanol precipitated, and redissolved in water. The poly(A) was 5 '-end-labeled (below) and resolved in $10 \%$ or $14 \%$ polyacrylamide $/ 7 \mathrm{M}$ urea gels. Individual bands, or groups of bands, were visualized by autoradiography, excised, and extracted from the gel slices. 
Oligoribonucleotides were $5^{\prime}$-end-labeled by using T4 polynucleotide kinase and $\left[\gamma^{-32} \mathrm{P}\right] \mathrm{ATP}$. For experiments to compare the effects of $\mathrm{MnCl}_{2}$ and $\mathrm{MgCl}_{2}$, the VGF 30-mer primer was labeled in $50 \mathrm{~mm}$ HEPES-NaOH $(\mathrm{pH} 8.0), 10 \mathrm{mM} \mathrm{MgCl}_{2}$ or $\mathrm{MnCl}_{2}$, for $20 \mathrm{~min}$ at $37^{\circ} \mathrm{C}$. For other experiments, primers were labeled in $50 \mathrm{~mm}$ Tris- $\mathrm{HCl}(\mathrm{pH} 8.0), 5 \mathrm{~mm}$ DTT, and $10 \mathrm{~mm}$ $\mathrm{MgCl}_{2}$, for $30 \mathrm{~min}$ at $37^{\circ} \mathrm{C}$, followed by a $15-\mathrm{min}$ incubation at $65^{\circ} \mathrm{C}$.

\section{Polyadenylation assays}

For experiments to compare the effects of $\mathrm{MnCl}_{2}$ and $\mathrm{MgCl}_{2}$ the $5^{\prime}$ phosphorylated primer reaction $\mathrm{mix}$ (above) was diluted with 9 volumes of $50 \mathrm{~mm}$ Tris- $\mathrm{HCl}(\mathrm{pH} 9.0), 5 \mathrm{~mm}$ 2-mercaptoethanol, and $1 \mathrm{~mm}$ ATP or other nucleoside triphosphate to give the complete reaction mixture. In other experiments, 2-mercaptoethanol in the dilution buffer was substituted with 4.5 mM DTT. In the initial assay of column fractions (Fig. ID), $0.6 \mathrm{mM} \mathrm{MnCl}_{2}$ was also present for consistency with previous studies (Moss et al. 1975; Shuman and Moss 1988b; Gershon et al. 1991). After the time zero sample $(2 \mu 1)$ had been transferred to an equal volume of formamide containing $0.1 \%$ (vol $/ \mathrm{vol}$ ) SDS and $2.5 \mathrm{mM}$ EDTA, the reaction was started by diluting VP55 with the complete reaction mixture. In all experiments other than those in which various primer/VP55 ratio were assayed, the calculated final concentration of VP55 was $27.4 \mathrm{nM}$ (after a 9.3-fold dilution into the assay), and the VGF 30-mer primer and related primers with 3 '-oligo(A) extensions were calculated to be present in 3.6-fold molar excess over VP55. After various times of incubation at $30^{\circ} \mathrm{C}$, further $2-\mu \mathrm{l}$ samples were taken as described above. Products were resolved in $10 \%$ (unless noted otherwise) polyacrylamide $/ 7 \mathrm{M}$ urea gels in Tris/borate/EDTA buffer. Unextended primer was quantitated on a Betascope 603 blot analyzer (Betagen), a background value subtracted, and the resulting value expressed as a fraction of the amount present at time zero.

\section{Acknowledgments}

We thank Norman Cooper for tissue culture and the preparation of purified virus.

The publication costs of this article were defrayed in part by payment of page charges. This article must therefore be hereby marked "advertisement" in accordance with 18 USC section 1734 solely to indicate this fact.

\section{References}

Broyles, S.S. and B. Moss. 1987. Sedimentation of an RNA polymerase complex from vaccinia virus that specifically initiates and terminates transcription. Mol. Cell Biol. 7: 7-14.

Butler, J.S. and T. Platt. 1988. RNA processing generates the mature $3^{\prime}$ end of yeast $\mathrm{CYC1}$ messenger RNA in vitro. Science 242: 1270-1274.

Cheley, S. and H. Bayley. 1991. Assaying nanogram amounts of dilute protein. Biotechniques 10: 730-732.

Christofori, G. and W. Keller. 1988. 3' Cleavage and polyadenylation of mRNA precursors in vitro requires a poly(A) polymerase, a cleavage factor, and a snRNP. Cell 54: 875-889.

- 1989. Poly(A) polymerase purified from HeLa cell nuclear extract is required for both cleavage and polyadenylation of pre-mRNA in vitro. Mol. Cell Biol. 9: 193-203.

Coleman, M.S. and M.R. Deibel. 1983. Terminal deoxynucleotidyl transferase. In Enzymes of nucleic acid synthesis and modification (ed. S.T. Jacob), vol. 1, pp. 93-118. CRC Press, Boca Raton, FL.

Edmonds, M. 1990. Polyadenylate polymerases. Methods Enzymol. 181: 161-170.

Fuerst, T.R., E.G. Niles, F.W. Studier, and B. Moss. 1986. Eukaryotic transient-expression system based on recombinant vaccinia virus that synthesizes bacteriophage T7 RNA polymerase. Proc. Nat1. Acad. Sci. 83: 8122-8126.

Gershon, P.D., B.-Y. Ahn, M. Garfield, and B. Moss. 1991. Poly(A) polymerase and a dissociable polyadenylation stimulatory factor encoded by vaccinia virus. Cell 66: 12691278.

Gilmartin, G.M. and J.R. Nevins. 1989. An ordered pathway of assembly of components required for polyadenylation site recognition and processing. Genes \& Dev. 3: 2180-2189.

Hagler, J. and S. Shuman. 1992. A freeze-frame view of eukaryotic transcription during elongation and capping of nascent mRNA. Science 255: 983-986.

Irniger, S., C. Egli, and G.H. Braus. 1991. Different classes of polyadenylation sites in the yeast Saccharomyces cerevisiae. Mol. Cell Biol. 11: 3060-3069.

Kates, J. and J. Beeson. 1970. Ribonucleic acid synthesis in vaccinia virus. II. Synthesis of polyriboadenylic acid. J. Mol. Biol. 50: 19-33.

Lingner, I., I. Radtke, E. Wahle, and W. Keller. 1991a. Purification and characterization of poly(A) polymerase from Saccharomyces cerevisiae. J. Biol. Chem. 266: 8741-8746.

Lingner, J., J. Kellermann, and W. Keller. 1991b. Cloning and expression of the essential gene for poly(A) polymerase from S. cerevisiae. Nature 354: 496-498.

Littauer, U.Z. and H. Soreq. 1982. Polynucleotide phosphorylase. In The enzymes (ed. P.D. Boyer), vol. XV, pp. 517-553. Academic Press, New York.

Moore, C.L. and P.A. Sharp. 1985. Accurate cleavage and polyadenylation of exogenous RNA substrate. Cell 41: 845-855.

Moss, B., O. Elroy-Stein, T. Mizukami, W.A. Alexander, and T.R. Fuerst. 1990. New mammalian expression vectors (product review). Nature 348: 91-92.

Moss, B., P. Earl, and N. Cooper. 1991. Expression of proteins in mammalian cells using vaccinia. In Current protocols in molecular biology (ed. F.M. Ausubel, R. Brent, R.E. Kingston, D.D. Moore, J.G. Seidman, J.A. Smith, and K. Struhll, vol. 2, pp. 16.15.1-16.19.8. Greene/Wiley, New York.

Moss, B., E.N. Rosenblum, and A. Gershowitz. 1975. Characterization of a polyriboadenylate polymerase from vaccinia virions. J. Biol. Chem. 250: 4722-4729.

Nevins, J.R. and W.K. Joklik. 1975. Poly(A) sequences of vaccinia virus messenger RNA: Nature, mode of addition and function during translation in vitro and in vivo. Virology 63: $1-14$.

-1977. Isolation and partial characterization of the poly(A) polymerases from HeLa Cells infected with vaccinia virus. J. Biol. Chem. 252: 6939-6947.

Osborne, B.I. and L. Guarente. 1989. Mutational analysis of a yeast transcriptional terminator. Proc. Natl. Acad. Sci. 86: 4097-4101.

Proudfoot, N. 1991. Poly(A) signals. Cell 64: 671-674.

Raabe, T., F.J. Bollum, and I.L. Manley. 1991. Primary structure and expression of bovine poly(A) polymerase. Nature 353: 229-234.

Rohrmann, G., L. Yuen, and B. Moss. 1986. Transcription of vaccinia virus early genes by enzymes isolated from vaccinia virions terminates downstream of a regulatory sequence. Cell 46: 1029-1035.

Romanos, M.A., A.J. Makoff, N.F. Fairweather, K.M. Beesley, D.E. Slater, F.B. Rayment, M.M. Payne, and J.J. Clare. 1991. 
Expression of tetanus toxin fragment $C$ in yeast: Gene synthesis is required to eliminate fortuitous polyadenylation sites in AT-rich DNA. Nucleic Acids Res. 19: 1461-1467.

Russo, P., W.-Z. Li, D.M. Hampsey, K.S. Zaret, and F. Sherman. 1991. Distinct cis-acting signals enhance 3 ' endpoint formation of CYC1 mRNA in the yeast Saccharomyces cerevisiae. EMBO \%. 10: 563-571.

Ryner, L.C., Y. Takagaki, and J.L. Manley. 1989. Multiple forms of poly(A) polymerases purified from HeLa cells function in specific mRNA 3'-end formation. Mol. Cell Biol. 9: 42294238.

Schnierle, B.S., P.D. Gershon, and B. Moss. 1992. Cap-specific mRNA (nucleoside- $\mathrm{O}^{2}$-)-methyltransferase and poly(A) polymerase stimulatory activities of vaccinia virus are mediated by a single protein. Proc. Natl. Acad. Sci. 89: 28972901.

Sheets, M.D. and M. Wickens. 1989. Two phases in the addition of a poly(A) tail. Genes \& Dev. 3: 1401-1412.

Shuman, S. and B. Moss. 1988a. Factor-dependent transcription termination by vaccinia virus RNA polymerase: Evidence that the cis-acting termination signal is in nascent RNA. $J$. Biol. Chem. 263: 6220-6225.

- 1988b. Vaccinia virus poly(A) polymerase: Specificity for nucleotides and nucleotide analogs. I. Biol. Chem. 263: 8405-8412.

Takagaki, Y., L.C. Ryner, and J.L. Manley. 1988. Separation and characterization of a poly(A) polymerase and a cleavage specificity factor required for pre-mRNA polyadenylation. Cell 52: $731-742$.

Wahle, E. 1991a. A novel poly(A)-binding protein acts as a specificity factor in the second phase of messenger RNA polyadenylation. Cell 66: 759-768.

- 1991b. Purification and characterization of a mammalian polyadenylate polymerase involved in the $3^{\prime}$ end processing of messenger RNA precursors. I. Biol. Chem. 266: 3131-3139.

Wickens, M. 1990a. How the messenger got its tail: addition of poly $(\mathrm{A})$ in the nucleus. Trends Biochem. Sci. 15: 277-281.

.1990b. In the beginning is the end: Regulation of poly(A) addition and removal during early development. Trends Biochem. Sci. 15: 320-324.

Yuen, L. and B. Moss. 1986. Multiple 3' ends of mRNA encoding vaccinia virus growth factor occur downstream of $\mathrm{T}$ clusters. I. Virol. 60: 320-323.

- 1987. Oligonucleotide sequence signaling transcriptional termination of vaccinia virus early genes. Proc. Natl. Acad. Sci. 84: 6417-6421.

Zaret, K.S. and F. Sherman. 1982. DNA sequence required for efficient transcription termination in yeast. Cell 28: 563573. 


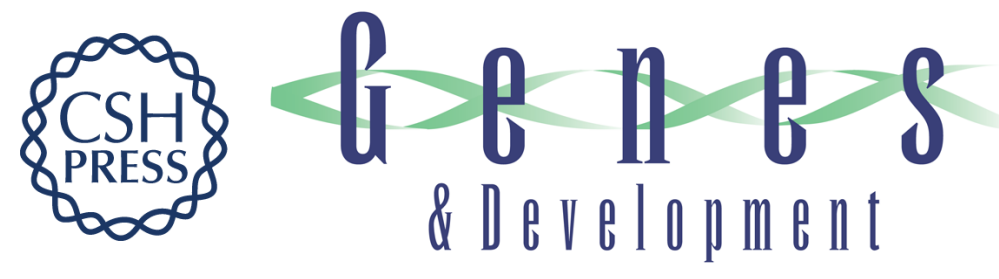

\section{Transition from rapid processive to slow nonprocessive polyadenylation by vaccinia virus poly(A) polymerase catalytic subunit is regulated by the net length of the poly(A) tail.}

P D Gershon and B Moss

Genes Dev. 1992, 6:

Access the most recent version at doi:10.1101/gad.6.8.1575 $\begin{array}{ll}\text { References } & \begin{array}{l}\text { This article cites } 38 \text { articles, } 19 \text { of which can be accessed free at: } \\ \text { http://genesdev.cshlp.org/content/6/8/1575.full.html\#ref-list-1 }\end{array}\end{array}$

License

Email Alerting Service

Receive free email alerts when new articles cite this article - sign up in the box at the top right corner of the article or click here.

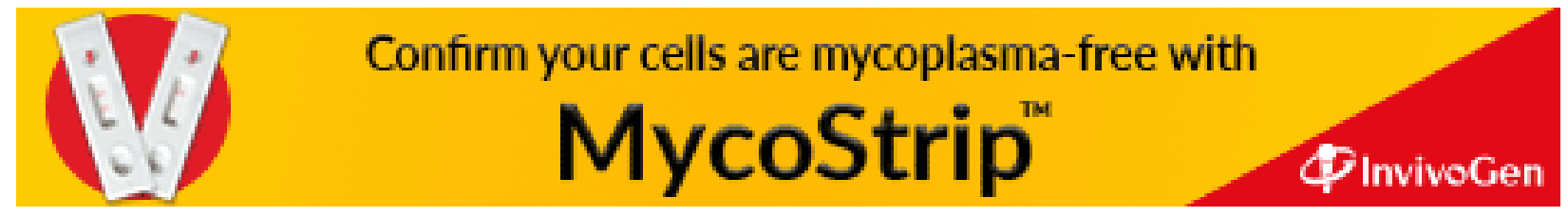

